\title{
MANZONIANA \\ Publicações Manzonianas no Brasil
}

\author{
Luigi Castagnola \\ Universidade Federal do Paraná
}

\section{RESUMO}

Em atenção a uma solicitação do Presidente da Sociedade Dante Alignieri. de Roma, dirigida ao Presidente do C.C.I.B.D.A. de Curitiba, o autor faz uma resenha das publicaçōes manzonianas no Brasil. Lembra que recorre neste ano de 1985 o segundo centenário do nascimento de Alessandro Rianzoni (1785-1985), o autor do famoso romance "OS NOIVOS". A seguir, o articulista fala dos artigos, estucios, ensaios, publicações manzonianas no Brasil. Fala da Comissão Manzoni, criada pelo Ministro Jarbas Passarinho e da atuaçāo dela. Depois analisa as diversas traduçōes de "OS NOIVOS", fazendo apreciações. Finalmente, salienta a excelente e completa tradução de Luis Leal Ferreira.

A Itália celebra com solenidade o segundo centenário do nascimento de Alessandro Manzoni (1785-1985).

Arturo Pompeati na sua monumental "Letteratura Italiana" escreve: "La Divina Commedia e I Promessi Sposi si guardano, a distanza di secoli, come le due massime espressioni poetiche della nostra civiltà cristiana: si guardano con un destino di integrazione e quasi di simmetria".'

A "Società Dante Alighieri" de Roma está organizando uma exposição de puiblicações manzonianas no mundo. Para tanto solicita a colaboração das instituições literárias dos diversos países "affinché collaborino ad una indagine sulla notorietà del romanzo I Promessi Sposi nel mondo, segnalandoci, per il rispettivo paese, le date della piú antica e della piú recente edizione del capolavoro manzoniano... I dati cosí raccolti saranno presentati in una manifestazione di

1 POMPEATI. A. Letteratura italiana. Torino, UTET, 1953, v.4, p.124. 
prestigioso livello alla Sede centrale di Palazzo Firenze, quale aggiornato e peculiare apporto della "Dante" agli studi su uno degli scrittori che maggiormente hanno onorato l'Italia e l'umanità".2

A Revista Letras, atendendo a tão honrosa solicitação publica uma breve nota sobre publicações manzonianas no Brasil.

Artigos, estudos, ensaios manzonianos publicados no Brasil.

LEONI G.D., Lezioni sul Manzoni. São Paulo, Nobel, 1951. LEONI, G.D., Guida bibliografica per lo studio del Manzoni. São Paulo, Nobel, 1950.

QUERIN, Edoardo, “Carneade! Chi era costui?". Rassegna Brasiliana di Studi Italiani. San Paolo, v.z., n.3 (f.5), 1959.

QUERIN, Edoardo, Le tragedie di Alessandro Manzoni. Premessa: la poetica del Manzoni, Rassegna..., v.3, n.2 (f.8), $19600^{3}$

CASTAGNOLA, Luígi, “OS NOrvOS” de A.Manzoni no Brasil. Letras. Curitiba, n.10, 1959.

CASTAGNOLA, Luígi, Manzoni, Ieri e Oggi, Letras. Curitiba, n.19, 1972.

CAVALLI, Francesca, Visualização da Paisagem Manzoniana, no volume: Vida e Obra de Alessandro Manzoni; Ensaios. Brasília, INL, 1973. p.51-79.

MATARAZZO GARGIULO, Matilde, Alessandro Manzoni e a questão da língua italiana, no volume: Vida e obra; $p$. 81-106.

PONT PUJO, Josefina Tereza, A Apresentação dos Personagens nas Três Edições de "I Promessi Sposi", no volume: VIDA e Obra ..., p.107-18.

CASTAGNOLA, Luígi, Trajetória Existencial e Literária de Alessandro Manzoni, no volume: VIDA e Obra ..., p.1-28. QUERIN, Eduardo, Evolucão Filosófico-Estética de Alessandro Manzoni, no volume: VIDA e Obra ..., p.119-48.

FERRO, Fioravante Valentino, Conversão e Sentido da "Provida Sventura" na Obra Manzoniana, no volume: VIDA e Obra ..., p.149-78.

PETTINE, Matilde, Visão Sócio-econômica de Alessandro Manzoni, no "I Promessi Sposi”, no volume: VIDA e Obra ..., p. 179-212.

GalefFi, Romano, Arte e Moral no Pensamento Estético de

2 Cf. carta do presidente da "Bocietá Dante Alighieri de Roma, ao presidente do C.C.I.B.D.A. de Curitiba, em data dé Roma, $28 \mathrm{Mag} .1985$.

3 Est? "Rassogna...", fundada e dirigida pelo humanista G.D.Leonl, publicou muitos artigos sobre Manzoni ou assuntos manzonianos. 
Alessandro Manzoni, no volume: VIDA e Obra..., p. 213-40.

VALENTE, Antonio, Aspectos da Biografia e da Conversão de Alessandro Manzoni, no volume: VIDA e Obra ..., p. 29-49.

QUERIN, Edoardo, La funzione del dolore nell'opera del Manzoni, Rassegna Brasiliana di Studi Italiani, São Paulo, $\mathrm{n}^{\circ} 2,1959$.

LEONI, G. D., Storia e questione della lingua italiana dalle origini al Manzoni. Revista da Universidade Católica, São Paulo, $\mathrm{n}^{\circ} 2,1952$.

$$
* * *
$$

Muitos outros estudos sobre Manzoni, sua arte, sua vida e sua obra foram publicados no Brasil, cuja informação bibliográfica deixamos de apresentar por desconhecê-la. Cf. CASTAGNOLA "OS NOIVOS de A. Manzoni no Brasil".

o "Centro Cultural Italo-Brasileiro Dante Alighieri" de Curitiba, publicou o estudo "Alexandre Manzoni - O Autor de "OS NOIVOS" para prestar homenagem a Manzoni no primeiro centenário de sua morte.4

\section{O Ministro Jarbas Passarinho e Manzoni}

O Ministro Jarbas Passarinho, quando à testa do Ministério da Educaçāo e Cultura, foi o autor da Portaria No 723, de 5 de outubro de 1972 que manifesta o apreço e a estima daquele homem público por Manzoni e pela sua obra artística e literária. Essa Portaria merece ser transcrita aqui pela sua importância. Ela vem mostrar não somente a simpatia do Ministro Jarbas Passarinho para com Manzoni, mas também o alto conceito que o Governo brasileiro tinha de Alessandro Manzoni.

Eis o texto da Portaria:

PORTARIA No 723, DE 5 DE OUTUBRO DE 1972.

O Ministro de Estado da Educação e Cultura, no uso de suas atribuições, e considerando que a 22 de maio de 1973 transcorrerá o primeiro centenário da morte do poeta e romancista italiano, ALESSANDRO MANZONI, e desejando que o Ministério da Educação e Cultura, na oportunidade, preste homenagem à cultura e ao povo italiano,

4 CAstagnols. L. Alexandre Manzoni, o autor de Os Noivos. Curitiba, Ed. Lud, 1973. 


\section{RESOLVE}

Art. $1^{9}$ - Patrocinar a publicação de uma edição bilingive de I FROMESSI SPOSI (OS NOIVOS) e de uma miscelânea de ensaios sobre a vida e a obra de ALESSANDRO MANZONI.

Art. 2." - Designar os professores a seguir indicados para realizar esta missão:

1. Dr. GIULIO DAVIDE LEONI, professor de Lingua e Literatura Italiana da Pontificia Universidade Católica de Sāo Paulo e da Universidade Mackenzie;

2. Dra. MATILDE MATARAZZO GARGIULO, professora de Filologia Romântica da Faculdade de Letras da Universidade Federal do Rio de Janeiro e da Faculdade de Humanidades Pedro II;

3. Dr. CELSO CUNHA, professor de Lingua Portuguesa da Faculdade de Letras da Universidade Federal do Rio de Janeiro e da Faculdade de Humanidades Pedro II;

4. Dr. ANTONIO VALENTE, professor de Latim do Colégio Militar do Rio de Janeiro e do Estado da Guabara;

5. Dr. ANTONIO JOAQUIM DE FIGUEIREDO, professor de Lingua Portuguesa da Faculdade de Humanidades Pedro II.

Art. $3^{\circ}$ - A Comissão acima designada poderá contratar o serviço de um tradutor brasileiro, residente no País e entender-se com o Instituto Nacional do Livro para que sejam publicadas a edição bilíngie e a miscelânea de ensaios, a primeira até dezembro e a segunda até 22 de maio de 1973.

\section{JARBAS G. PASSARINHO.}

A Comissão Manzoni, criada pela Portaria do Ministro Jarbas Passarinho convidou a colaborar na Coletânea os professores Alfredo Bosi, Francesca Cavalli, Josefina Tereza Pont Pujó, Fioravante Valentino Ferro, Matilde Pettine, Edoardo Querin, Romano Galeffi, Iuís Castagnola, Wilton Cardoso e Antonio Sales.

Dos professores "convidados a colaborar na Coletânea, a Comissão Manzoni recebeu os seguintes trabalhos:

a) Visualização da Paisagem Manzoniana, de Francesca Cavalli - Universidade de São Paulo; b) Alessandro Manzoni e a questão da língua italiana, de Matilde Matarazzo Gargiulo - Universidade Federal do Rio de Janeiro e Faculdade de Humanidades Pedro II; c) A Apresentacão dos Personagens nas Três Edições de "I Promessi Sposi", de Josefina Tereza Pont Pujo' - Universidade Mackenzie; d) Trajetória 
Existencial e Literária de Alessandro Manzoni, de Luis Casiagnola - Universidade Federal do Paraná; e) Evoluçāo Filosófico-Estética de Alessandro Manzoni, de Edoardo Querin - Universidade São José do Rio Preto; f) Conversão e Sentido da "Provida Sventura" na Obra Manzoniana, de Fioravante Valentino Ferro - Faculdade de Filosofia de Florianópolis; g) Visão Sócio-econômica de Alessandro Manzoni no "I Promessi Sposi", de Matilde Pettine - Universidade de Campinas; h) Arte e Moral no Pensamento Estético de Ales sandro Manzoni, de Romano Galeffi - Universidade Federal da Bahia e Instituto Brasileiro de Filosofia; i) Aspectos da Biografia e da Conversão de Alessandro Manzoni, de Antonio Valente - Colégio Militar do Rio de Janeiro".5

A Comissão Manzoni não conseguiu, entretanto, preparar a traduçāo do famoso romance.

O Instituto Nacional do Livro, do Ministério da Educação e Cultura, publicou os ensaios, que foram enviados à Comissāo Manzoni, reunidos no aprimorado volume Vida e Obra de Alessandro Manzoni - Ensaios.

Pelo exposto, o Governo Brasileiro, o mundo universitário e a imprensa brasileira prestaram uma homenagem expressiva ao grande escritor lombardo por ocasiāo do primeiro centenário de suá morte.

$$
\because *:
$$

III

\section{TRADUTORES E TRADUÇŌES DE MANZONI}

O primeiro tradutor de Manzoni para o português penso tenha sido o Imperador Dom Pedro II. Com efeito, Ferruccio Rubbiani, na introdução à edição em língua italiana de "I Promessi Sposi", por ele publicada em São Paulo, falando da ode famosa "Cinque Maggio" do poeta milanês, diz que "o Imperador Dom Pedro II traduziu-a em português"."

Não falarei da tradução do romance manzoniano que a Editora-Livraria Garnier vendia no Rio de Janeiro em dois volumes enfeitados. Embora tenha visto outrora essa tradução e edição de "I Promessi Sposi", não a tenho em mãos, e não posso pronunciar apreciações. Alguém todavia escreveu que "a tradução nāo teria sido feita do italiano, mas sim da trađução francesa".

5 Apresentou a Colctínea... o Professor Antonio Jogquim de Firueircdo. do Coléglo Mrilltar do Rlo de Janelro e da Faculdade de Humanldades Pedro II, com as palavras: Razoo desta Ce!ctünea.

C1. CASTAGXolA, L. Os Noivos de A.Manzonl no Brasil, Letras (10):1-14, 1959. 
Aqui vamos mencionar três traduções.

"OS NOIVOS", Rio de Janeiro, Pongetti, 1944. Tradução de Marina Guaspari.

"OS NOIVOS", São Paulo, Paulinas, 1957.

"OS NOIVOS", Petrópolis, Vozes, 1951. Tradução de Luís Leal Ferreira.

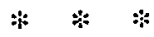

a)

“OS NOIVOS” - Tradução de Marina Guaspari. Rio de Janeiro, Pongetti, 1944.

Esta tradução é a primeira que conheci no Brasil. Comprei um exemplar do livro na Livraria Ghignone, em Curitiba. Estava feliz e cheio de esperança; pois pensava que tinha em mãos, em lingua portuguesa, a obra-prima da prosa italiana, o famoso romance "I PROMESSI SPOSI" - disseme, em italiano, o velho Ghignone, ao qual me havia dirigido na loja da Rua 15 de Novembro, com a intenção de arrumar livros que servissem pa aros meus alunos do curso de Língua e Literatura Italiana na Universidade Federal do Paraná, e na Faculdade Católica de Filosofia, Ciências e Letras de Curitiba. Comecei a ler com grande sofreguidão e esperança. Mas, comparando o texto português com o texto italiano ${ }^{\top}$ a minha desilusão foi súbita. Continuando a leitura, cheguei a uma conclusão desalentadora: o texto todo desta tradução portuguesa do belo, do doce, do milagroso romance italiano, da obra-prima da prosa italiana, "I PROMESSI SPOSI", apareceu diante de mim como "um espetáculo tal de arrancar as lágrimas de um olho de porcelana", para usar uma expressão de Papini. ${ }^{8}$

Nem se compreende como esta tradução tenha sido reproduzida numa edição da Tipografia do Centro, em Porto Alegre, na coleção de romances "A Nação". E agora, também a prestigiosa Editora Abril Cultural recorreu ao texto da tradução de Marina Guaspari para fazer figurar "OS NOIVOS" de Manzoni na sua coleção de "Clássicos Modernos".

Seguindo um método totalmente censurável, a tradutora pula trechos ao longo do texto, outros resume em poucas palavras, e até deixa de traduzir os trechos mais conhecidos, como, por exemplo, "L'addio ai monti".

Para que o leitor não pense que eu seja injusto ou tendencioso, vou aqui reproduzir o que o jornalista Edson Nery da Fonseca escreveu no DIARIO DE PERNAMBUCO, em

7 O texto itallano, que usel na comparaçio, fol o da edicăo Ulrlco Hoepll, Edatore Llbrato della Real Casa, Mllano. 1918.

B PAPINI. Glovannt. La pietra infernale. Brescia, Morcellana, 1934. p.271.

9 Cr I promessi sposi, cap. VIII. 
9/9/1951. Então era ele Bibliotecário da famosa Faculdade de Direito do Recife.

"A edição dos PROMLESSI SPOSI que encontrei no Recife, foi a pior possivel ... a horrorosa "tradução" da sra. Marina Guaspari, editada pelos Irmãos Pongetti". Após narrar coisas interessantes sobre o livro de Manzoni, afirmando que devia estar em todas as Faculdades de Direito, escreve textualmente: "Pude verificar como foi criminosamente mutilada a tradução de OS NOIVOS, editada em 1944 pelos Irmāos Pongetti. A sra. Marina Guaspari devia ser punida pelo governo italiano e proibida de traduzir pelo nosso Ministério da Educação". ${ }^{10}$

O autor pernambucano protesta com muita justiça contra estas traduçōes que deturpam grandes obras e grandes artistas e enganam os leitores.

O tradutor deixou de traduzir, mais ou menos, 250 páginas do original!

$$
* * *
$$

b)

"OS NOIVOS" - Tradução de anônimo. São Paulo, Paulinas, 1957.

As Edições Paiulinas são muito beneméritas da boa imprensa. Não queremos poupar elogios a esta empresa editorial. As publicações paulinas contribuem muito mesmo para a difusão da cultura e da boa imprensa em todos os sentidos. Além de preciosos livros de formação civica e religiosa, publicam, também, uma coleção literária: "Os Grandes Romances do Cristianismo". Entre eles figura "OS NOIVOS" de Alexandre Manzoni. ${ }^{11}$

Umas ligeiras observaçōes a respeito desta tradução.

$O$ leitor gostaria de conhecer o nome de quem fez a tradução de uma obra tão famosa e importante.

Seria desejável uma introdução, que explicasse os motivos pelos quais foram deixados certos trechos do texto original. Por que motivo, por exemplo, faltam por completo os capitulos: XXVIII, XXIX, XXX, XXXI, XXXII.

$$
\because * \because
$$

"OS NOIVOS", tradução de Luis Leal Ferreira. Editora Vozes, Petrópolis. Vozes, 1951.12

- Fdson Nery da FONSECA. Traduçes. Diário de Pernambuco, Reclfe, 9 set. 1951.

11 E de se sal!entar que a traduç̄o năo esmerada.

12 Os Noivos: histỏria mllanesa do século XVIr, descoberta e refundida por Alexandre Manzant. Traducáo direia do oricinsl. com respelto do estilo, por Luis Leal Ferreira. Petrópolis. Vozes, 1951. 
Finalmente: o grande livro de Manzoni tem, no Brasil, uma tradução completa, "de fio a pavio, que reproduz com exatidão o original e pode oferecer idéia assaz aproximada deste. $\mathrm{E}$ justamente pelo respeito que tenho à forma, na produção literária, foi que declarei a minha tradução "com respeito de estilo". Por outro lado, dizendo-a "direta do original", quis dar a entender que não era feita de outra lingua". ${ }^{13}$

O acima citado jornalista de Pernambuco, Edson Nery da Fonseca, escreveu a respeito desta magnífica tradução: "Trabalho exaustivamente bem feito pelo sr. Luís Leal Ferreira ... Podemos dizer que ele tem uma paciência de frade. Uma pachorra semelhante à daqueles monges antigos, que copiavam livros inteiros e ainda se davam ao trabalho de decorar as letras capitulares: trabalho de artesão e de artista, ao mesmo tempo. A tradução dos PROMESSI SPOSI feita pelo sr. Luís Leal Ferreira, é um trabalho assim: revela a pachorra do artesão e a sensibilidade de um artista". ${ }^{14}$

Luis Leal Ferreira fez uma excelente trađução de I PROMESSI SPOSI. Traduziu, por longo tempo, para a Editora Vozes; e por iniciativa do seu antigo diretor, Frei Tomás Bogmeier "empreendeu, não sem relutância, a tradução de "I Promessi Sposi", do imortal Manzoni. Com relutância justamente por se tratar de uma obra clássica, de fama mundial, e cujo original eu já possuía, comprado no Recife, onde estudei, e de onde saí no fim de 1913.

Em todo caso, homem pobre, com pesados encargos de familia, lutando duramente pela vida, acabei aceitando a incumbência, de que aquele religioso me dizia inteiramente capaz ... Devo dizer-lhe que, se me perguntarem o que penso de minhas traduçōes, tenho apenas a dizer o seguinte: que procuro ser decente nos meus trabalhos e fiel na tradução. Por princípio, só faço traduçōes literais, porque tenho sumo respeito aos autores, tanto no tocante ao seu pensamento como no tocante ao modo e às próprias palavras com que o exprimiram. Fundo e forma. Não me concedo senão a liberdade mínima que se faz de mister para que a tradução seja aceitável na língua para a qual é feita. Fidelidade a mais estrita possível tanto no fundo como na forma, elegância, correção e clareza na língua para que se trađuz, eis os princípios que norteiam meus modestos trabalhos ... Eu gostaria muito de fazer uma tradução definitiva de "I Promessi Sposi", ou seja, a que fiz, escoimada dos defeitos ... Em todo caso, o livro de Manzoni já tem realmente no Brasil uma tradução completa, de fio a pavio, que, mesmo com defeitos, reproduz

13 Cf. carta do trndutar ao autor do presente artigo, em 1961.

14 FONBECA. 
com exatidāo o original e pode oferecer idéia aproximada deste". 15

Quisemos, de propósito, fazer esta longa citação de uma carta a mim dirigida pelo Senhor Luis Leal Ferreira, que me comoveu profundamente. Agradecia-me ele pelas críticas favoráveis que eu havia feito à sua tradução da obraprima de Manzoni, publicadas na revista Letras da Universidade Federal do Paraná. ${ }^{16}$

A antiga "Comissão Manzoni", criada pelo Ministros Jarbas Passarinho podia bem utilizar esta tradução de Luís Leal Ferreira. Oxalé apareçam outras autoridades e outros homens, italianos ou brasileiros, que façam uma edição bilínguie do imortal romance, usando esta trađução. Bem o merece seu humilde, pobre e sofrido autor. Bem o merece Manzoni. Seria uma digna e proveitosa homenagem, no segundo centenário do seu nascimento, a Alessandro Manzoni.

\section{RIASSUNTO}

In attenzione ad una sollecitazione del Presidente della Società Dante Alighieri, di Roma, diretta al C.C.I.B.D.A. di Curitiba, l'articolista fa un prospetto delle pubblicazioni manzoniane nel Brasile. Ricorda che ricorre quest'anno il secondo centenario della nascita di Alessandro Manzoni (1785-1985), l'autore del famoso romanzo I PROMESSI SPOSI. Sono quindi indicati articoli, studi, saggi, Pubblicazioni manzoniene nel Brasile. Parla della Commissione Manzoni creata dal Ministro Jarbas Passarinho e di quello che essa fece. In seguito analizza le diverse traduzioni de "I PROMESSI SPOSI" in lingua portoghese. Mette in risalto la eccellente e completa traduzione di Luis Leal Ferreira.

\section{REFERENCIAS BIBLIOGRAFICAS}

1 CAStagnola, L. Alexandre Manzoni, o autor de Os Noivos. Curitiba, Ed. Lud, 1973.

2

3

\section{FONSECA,
1951.}

4 MaNZONI, A. Os noivos. Rio de Janeiro, Pongetti, 1944.

5

6

7 